\title{
Personalized E-Learning Environment based on Ontology to Improve Students' School Levels
}

\author{
Mohammed Amine ALIMAM \\ Laboratory of Computer science, \\ Operational research and Applied statistics (LIROSA) \\ Faculty of Science (FS), Tetouan, Morocco
}

\author{
Hamid SEGHIOUER \\ Laboratory of Computer science, \\ Operational research and Applied statistics (LIROSA) \\ Faculty of Science (FS), Tetouan, Morocco
}

\begin{abstract}
Personalization of learning is the core of current research in the E-learning area. For effective learning, a personalized content provided to each student remains necessary. Students who use this educational web-based applications aim at learning knowledge which corresponds to their expectations. However, their school level and interests are different. Thus, the system should recommend to students a learning content that match the most their knowledge levels and is interesting enough to keep their attention. This paper describe a method enabling system to classify students depending on their school levels. This method will allow a semantic classification of profiles integrated within ontology. Accordingly, the system will be able to categorize students in a definite profile based on their school level and make a decision about the interfaces content recommended by each type of profile. To evaluate the effectiveness of the proposed approach, an experiment was conducted on students from middle school. The experimental results show that, such a system recommends to each student a field of study (FoS) whose subjects taught will match the best their skills. The E-Learning content based on those subjects will allow the enhancement of student's school level.
\end{abstract}

\section{General Terms:}

E-Learning, Ontology

\section{Keywords:}

Information systems, Semantic Web, Ontology, domain model, user model, Personalization.

\section{INTRODUCTION}

The introduction of E-Learning concept has revolutionized the educational arena. It is offered in a new way that impact different types of learners [1]. E-Learning mode offers a greater flexibility for students to study almost anywhere at anytime. However students of different abilities need to receive different treatments. The system must be able to recommend to students the pedagogical content that matches the most their preferences and knowledge levels. Hence, it is of great importance to provide a system which can automatically adapt to learners' knowledge levels and intelligently recommend online resources that would favor and improve the learning [2]. This ability to provide content that are tailored to students is called personalization. In literature, several methods for content personalization were proposed [3, 4 , 5], the most used were cited in [6]: Information filtering, Recommendation, Personalized information query, Auto-fill forms. According to Resnick [7], recommendations concept is designed to support users in making choices without sufficient experiences of the alternatives. Recommendations are required in order to help learners finding the study area that match their abilities. Other possibility, that can be used to structure and model the educational domain in order to be shared by a group of students, is ontology based on semantic web, it's an explicit specification of a conceptualization or a model [8]. With the ontological approach proposed in a e-learning context, students can obtain the educational resources of interest dynamically and tailored to their interests. This would keep their attention and also motivate them. Sawang [9] emphasizes that student's satisfaction is a vital indicator influencing the overall success and quality of an e-learning system, it is a main factor that influences students' decisions to continue or drop-out of courses. This paper aims to investigate a technological learning-based method integrated into a system in order to recommend the most suitable FoS to students. According to these recommendations, the system prepares students to school success by supporting them through a remedial courses related to the proposed FoS. Finally, a hybrid system classified in two categories is suggested. The first one consists on an educational recommender system (ERS) [10] that use a specific method to recommend the FoS to students in accordance with their school levels. The second category is an E-Learning platform presenting pedagogical content in accordance with the FoS previously proposed to students. This paper is organized as follows. Sections 2, 3 and 4 describe some previous research related to the proposal. Section 5 details the construction of the ontology model. The student's profile personalization method, based on the FoS recommendation technique, is referred to in Section 6. Section 7 applies the proposed model to Moroccan educational system in order to affirm its relevance, and Section 8 shows how to personalize the web content depending on student's profile. Finally, Section 9 provides the concluding remarks.

\section{RECOMMENDATIONS IN AN E-LEARNING ENVIRONMENT}

E-Learning may include all types of technology-enhanced learning. It refers to the use of computer technology to deliver information 
and instruction to individuals, it is also evolving into systems consisting of a variety of technologies [11]. Moreover, E-Learning enables to adapt learning content in a more efficient way by using its recommendation side. However, recommendations in an E-Learning environment are widely covered by literature under various forms [12]:

- Recommendation of appropriate learning resources.

- Recommendation of actions that a learner should perform within the e-learning environment.

- Recommendation to extend the content of an e-learning system by related learning resources from the Web.

Indeed, due to the few number of system users in the E-Learning area, the number of approaches based on collaborative filtering is limited [13]. This gap will be resolved if the system included most students belonging to middle and high school (from 6th to 12th graders). In fact, this category of students' need a recommendation system able to guide them to the appropriate field and then to support them through the pedagogical content that match the most their abilities. As mentioned previously, when the system meet their need, students' satisfaction will be a main factor influencing their decisions to continue with it. Consequently, the number of young users will increase, which allows this system to succeed. Also, Such a system will no longer need to replace collaborative filtering by clustering, stereotyping, or rule-based techniques.

\section{PERSONALIZED RECOMMENDATIONS}

The E-Learning systems concern a wide disciplinary areas and intended for users with different knowledge levels, the personalization needs still cover:

- The content of the proposed learning activities, which may differ from the data themselves and also by the level of difficulty.

- The interface and functionalities of the system based on the construction of user's profile [14].

- The sequence of activities.

To fill those needs, the E-Learning systems use information about students that consist either by student's activities logs or by student's profile [13]. In the domain of recommender systems, different personalization techniques are combined to overcome the disadvantages of single personalization techniques, this is called a hybrid recommender system [15]. However, these approaches are statically, i.e., they cannot select the most appropriate technique [10]. For the specificity of educational area, the system can benefit from availability of students' school data (for example: personal information, school marks, FoS) to apply the appropriate recommendation method.

\section{ONTOLOGY AND SEMANTIC WEB}

With the emergence of Semantic Web, there has been much discuss on the Extensible Markup Language (XML) role in resources design for educational purposes (pedagogical/learning objects). If XML has to play an important role in creating resources (micro design), it still limited for reasons related to their exploitation and sharing, which involve its inability to be used for their indexing and location [16]. To fill this gap, the ontologies use remains essential. The term "ontology" has many different definitions, it has been widely exploited in many domains (e.g., medicine, education; and logistics) using it capacity to promote shareability of knowledge bases, knowledge organization, and interoperability between systems [6]. In educational area, ontological engineering [17] has become a recurring theme and privileged way to analyse, design and develop an E-Learning system. The specific contribution of ontological engineering for E-Learning is providing a structured and expressed representation shared by a community (human or artificial agents), which makes reference and guides their design. Psyche [18] add to this that it can provide a formal representation, coupled with an inference mechanism allowing to these environments to reason. To develop an ontology Noy [19] gives the main following reasons :

- To share common understanding of the information structure among community (human or artificial agents).

-To enable reuse of domain knowledge.

On the other hand, the ontological engineering plays a principal role in the construction of learners' profiles. In fact, ontology based on semantic web is one of the possibilities of personalizing the learning process which is used for structuring and modeling a particular domain that is shared by a group of users in an organization.

\section{ONTOLOGY USE}

To exploit the semantic web for pedagogical purposes, Nilsson, Palmer, and Naeve [20] concluded that a conceptual modeling is necessary. Indeed, ontology provides a framework for making decision of the recommended web content. However, there is many reasons to develop an ontology, some of them are :

- To share common understanding of information structure among users or software agents.

- To enable reuse of domain knowledge

- To make domain assumptions explicit

- To separate domain knowledge from the operational knowledge

- To analyze domain knowledge

In this work, the ontology use will allow the construction of student's profile as well as the identification of pedagogical concepts and semantic links they have. This aims to represent the proposed model. The ontology schema (Fig. 1) consists of four upper level classes, namely:

—"StudentLevel" : Student's background, actuel level and his SLA (school level algorithm) results.

—"StudentPersonalInformation" : represents static and permanent student information and characteristics that concern student's interaction with E-Learning system.

—"Content" : Represents information relative to pedagogical content of student's interface.

—"InteractionPreference" : Student's preferences regarding interaction with the E-Learning system.

The purpose of this ontology is to exploit recommendations for students based on SLA algorithm, in order to personalize their web content. This E-Learning framework will support them during all their study.

\section{THE 'RMS' MODEL : RECOMMENDATION METHOD FOR STUDENTS}

In most school systems, students have to choose a FoS at the end of 9th grade middle school. They are required to follow a track which they have no prior idea if it is appropriate to their abilities. Given 


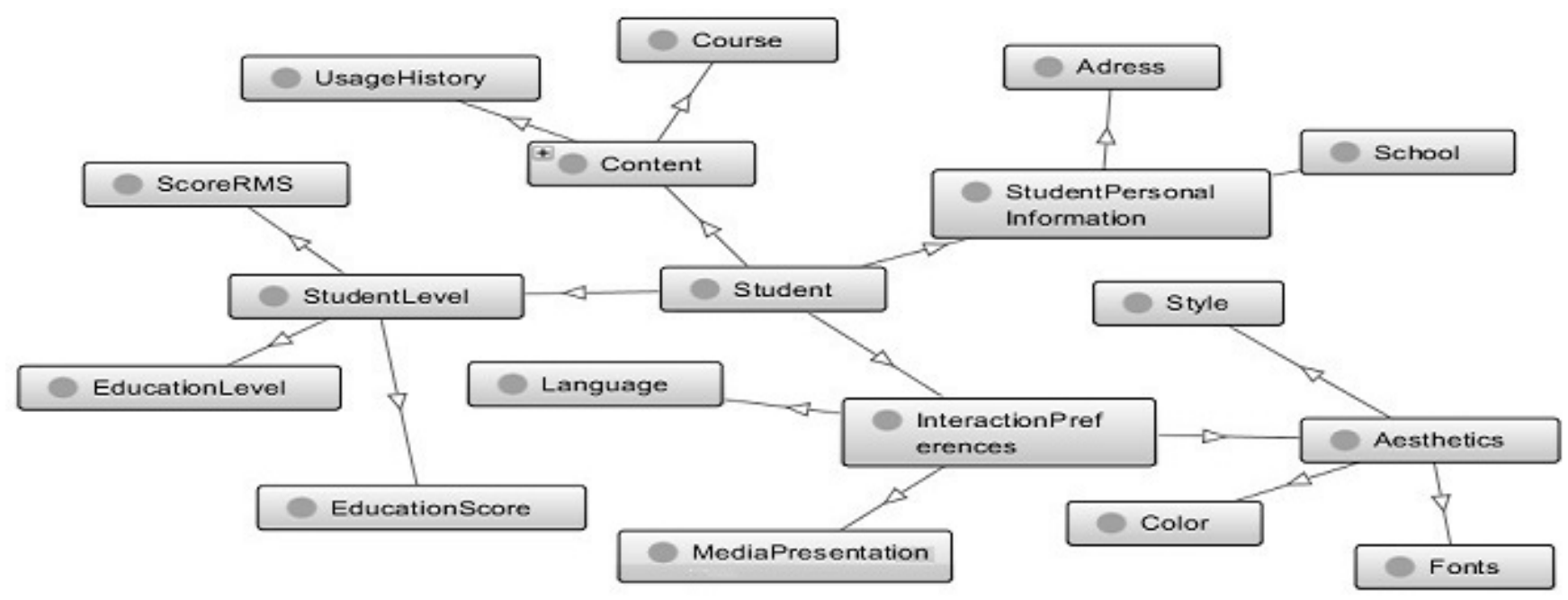

Fig. 1. Descriptive diagram of a part of ontology domain

the lack of permeability between pathways in traditional education systems, such decisions were often irrevocable [21]. These things should be considered before wasting time on a degree that students will not complete, especially as some FoS are more difficult than others, and some will not prepare you for the field you want to work in. However, students should have a good understanding of what will be expected of them academically before they make a decision. A simulation of abilities together with a previous preparation become necessary. Although if you decide you have chosen the wrong FoS, you can always switch to a different plan. Indeed, a RMS method based on students' previous school marks (psm) is proposed to simulate their abilities. The system will propose the most appropriate FoS to student and will personalize the student's interface with pedagogical content belonging to this same FoS. The goal is to provide to student the opportunity to be proactive in his choice.

On the other hand, to classify students according to their levels and their tendencies, most scholar systems use a weight called coefficient (credit hour) given in order to lead hierarchy of school subjects. In fact the coefficient reflect level or time requirements of different subjects. But, depending on which school system, coefficients can be used at high school or until university level. However the following method can be applied for both of them: Let $C_{i, j}$ the coefficient of subjects $M_{i}$ in the FoS $F_{j}$, the coefficients' matrix will be $C=\left(C_{i, j}\right)_{\substack{1 \leq i \leq p \\ 1<j<q}}$ with i the subjects' number and $j$ the existing FoS number:

$$
C_{i j}=\left(\begin{array}{ccc}
C_{1,1} & \ldots & C_{p, 1} \\
\vdots & \ddots & \vdots \\
C_{1, q} & \cdots & C_{p, q}
\end{array}\right)_{\substack{1 \leq i \leq p \\
1 \leq j \leq q}}
$$

The student's school mark in subject $M_{i}$ at psm corresponds to $N_{i}$. The system calculates the student's mark by FoS as follows: For each $F_{j}$, the corresponding mark for 'Student $k$ ' is $N_{F_{j, k}}$ as:

$$
N_{F_{j, k}}=\frac{\sum_{i=1}^{p}\left(C_{i, j} \times N_{i}\right)}{\sum_{i=1}^{p} C_{i, j}}
$$

Thus, the recommended FoS for 'Student $k$ ' is corresponding to the mark:

$$
N_{F_{k}}=\max \left(N_{F_{j, k}}\right)
$$

\section{APPLICATION OF 'RMS' TO THE MOROCCAN EDUCATION SYSTEM}

The RMS method will be applied to the pre-university level of Moroccan educational system (MES), which includes six years of primary school, three years of secondary school college (SSC) and secondary school qualifying (SSQ) of three years. EGA will be applied to students in SSC. In this level, all subjects have same coefficient, whereas at SSQ each subject is weighted by coefficient depending on the FoS.

However, some students belonging to the MES are taken as an example. Their Grade Point Average (GPA) at the end of SSC are purposely taken close, to demonstrate that even if those students are considered by school at the same and must have approximatively the same pathways, their appropriate tracks are very distant. Next, the system will proceed to recommend the appropriate $\mathrm{FoS}$ to this sample of students.

A list of abbreviations is defined as follow:

-School sections: Experimental Sc (ES), Mathematics Sc (MS), Literature and Human Sc(LHS), Economic and Management Sc (EMS), Authentic Ed(AE), Industrial Technologies (IT), Applied Arts (AAr).

-School Series: Sciences of Life and Earth (SLE), Physics and Chemistry (PC) Agriculture Sc (AS), Mathematics Sc A- (MSA), Mathematics Sc - B - (MSB), Literature (Lt), 
Human Sciences (HS), Economic SC (ES), Accounting (Ac), Arabic Language (AL), Science of Sharia (SC) Mechanical (Mc) Electric (El), Applied Arts (AAr).

- Studied Materials: Arabic (Ar), the first living language (LL1), 2nd Foreign Language (FL2), Mathematics (Mt), History and Geography (HG), Sciences of Life and Earth (SLE), Physics and Chemistry (PC) Technology (Te), Islamic Education (IE), Arts Education (ArE), Physical Education (PE) Sociology (Soc). -Grade Point Average is GPA.

Table 1 presents school marks obtained, in different materials, by seven students at SSC level.

Table 1. students' school marks at CSC.

\begin{tabular}{cccccccccccccc}
\hline Sts/Mts & Ar & LL1 & FL2 & Mt & HG & SLE & PC & Te & IE & ArE & PE & Soc & GPA \\
\hline St 1 & 18 & 10 & 9 & 10 & 15 & 14 & 7 & 13 & 17 & 12 & 14 & 15 & $\mathbf{1 2 . 8 3}$ \\
St 2 & 12 & 14 & 13 & 18 & 11 & 14 & 16 & 13 & 13 & 11 & 16 & 13 & $\mathbf{1 3 . 6 7}$ \\
St 3 & 6 & 8 & 9 & 17 & 19 & 7 & 7 & 14 & 13 & 11 & 10 & 14 & $\mathbf{1 1 . 0 0}$ \\
St 4 & 10 & 12 & 11 & 14 & 11 & 12 & 12 & 13 & 10 & 10 & 11 & 11 & $\mathbf{1 0 . 2 5}$ \\
St 5 & 11 & 12 & 10 & 14 & 9 & 17 & 16 & 13 & 9 & 10 & 14 & 5 & $\mathbf{1 1 . 6 7}$ \\
St 6 & 15 & 17 & 17 & 5 & 17 & 7 & 4 & 6 & 13 & 12 & 11 & 16 & $\mathbf{1 1 . 6 7}$ \\
St 7 & 14 & 12 & 13 & 7 & 12 & 4.5 & 4 & 12 & 10 & 17 & 8 & 14 & $\mathbf{1 0 . 4 6}$ \\
\hline
\end{tabular}

For these recommendations for students, the current system is based only on the Grade Point Average (GPA) to assign them to their choices. These choices are influenced by social stereotypes related to their social origins [22], especially if student has close scores in all subjects (example 'Student 4'). Thus, the student choice is arbitrary. It is unfounded on his abilities or a clear vision of the chosen FoS. Also, if a same choice is maked by two students or more, the current system gives priority to the one that has the highest GPA, even if the other student is better in the important subjects of the chosen FoS. This gives a skewed orientation. To apply the RMS method, the coefficients' matrix $C=\left(C_{i, j}\right)$ is presented in Table 2 .

Table 2. Coefficients' matrix.

\begin{tabular}{ccccccccccccccc}
\hline SS & FoS & Ar & LL1 & FL2 & Mt & HG & SLE & PC & Te & IE & ArE & PE & Soc \\
\hline ES & SLE & 2 & 4 & 2 & 7 & 2 & 7 & 5 & 0 & 2 & 0 & 4 & 2 \\
& PC & 2 & 4 & 2 & 7 & 2 & 5 & 7 & 0 & 2 & 0 & 4 & 2 \\
& AS & 2 & 4 & 2 & 7 & 2 & 5 & 5 & 0 & 2 & 0 & 4 & 2 \\
MS & MSA & 2 & 4 & 2 & 9 & 2 & 3 & 7 & 0 & 2 & 0 & 4 & 2 \\
& MSB & 2 & 4 & 2 & 9 & 2 & 0 & 7 & 3 & 2 & 0 & 4 & 2 \\
LHS & Lt & 4 & 4 & 4 & 1 & 3 & 0 & 0 & 0 & 2 & 0 & 4 & 3 \\
& HS & 4 & 3 & 3 & 1 & 4 & 0 & 0 & 0 & 2 & 0 & 4 & 4 \\
EMS & ES & 2 & 3 & 2 & 4 & 3 & 0 & 0 & 0 & 2 & 0 & 4 & 2 \\
& Ac & 2 & 3 & 2 & 4 & 2 & 0 & 0 & 0 & 2 & 0 & 4 & 2 \\
AE & AL & 13 & 3 & 2 & 1 & 3 & 0 & 0 & 0 & 4 & 0 & 4 & 2 \\
& SC & 10 & 3 & 2 & 4 & 2 & 0 & 0 & 0 & 12 & 0 & 4 & 2 \\
IT & Mc & 2 & 4 & 2 & 7 & 0 & 0 & 5 & 10 & 2 & 0 & 4 & 2 \\
& El & 2 & 4 & 2 & 7 & 0 & 0 & 5 & 8 & 2 & 0 & 4 & 2 \\
AAr & AAr & 2 & 4 & 2 & 2 & 0 & 0 & 0 & 0 & 2 & 26 & 4 & 2 \\
\hline
\end{tabular}

This matrix has a large impact on recommendations for students. Thus, using equation (1) for 'Student 1' in relation to FoS 1 (SVT), the score is:

$$
N_{F_{1,1}}=\frac{(2 \times 18)+(\ldots)+(2 \times 15)}{(2+\ldots+2)}=12.08
$$

In the same way, the matrix of recommendations for students is established (Table 3 ).

However, each student will be assigned to a FoS following equation (2). For example, the score $N_{F_{3}}$ of the recommended FoS related to 'Student 3' is:

$$
\max \left(N_{F_{j}}\right)=\max (10.73, \ldots, 10.82)=12.41
$$

Thus, the FoS 'SE' corresponding to score 12.41, will be recommended to 'Student 3'.

The results of this step show that even if the GPA of students are close, their recommendations are significantly different. This explains why the impact of GPA currently adopted on the student's orientation remains biased. These results, which are a kind of student's school level projection in the near future, give a preliminary idea about his real capacity in each FoS. This will permit to recommend the most suitable FoS to student.

- Findings :

As shown in the current system, the students' affectation is not established correctly, since it does not consider several factors. Thus, school system is dealing with a great loss of students' potential. Thereby, the RMS method propose a solution to this problem by evaluating students individually.

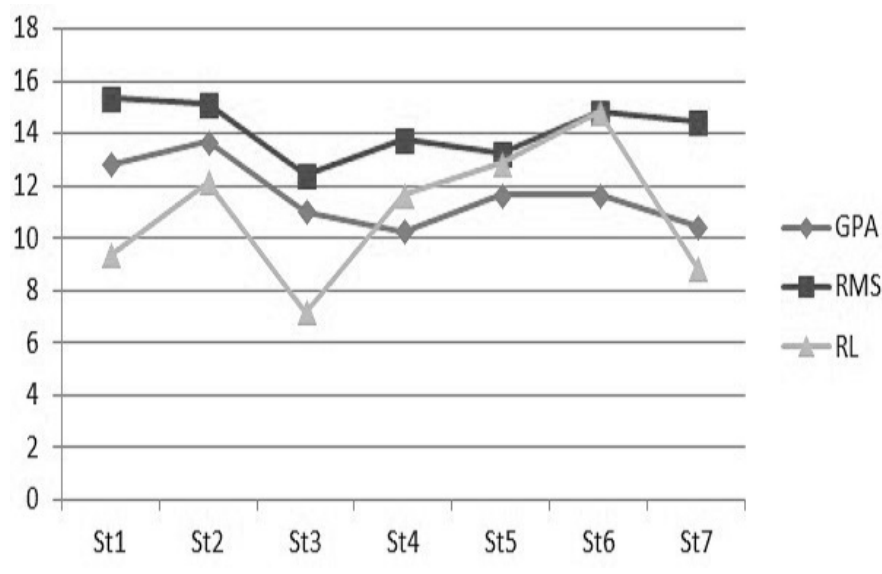

Fig. 2. Evolution of students' levels.

In Fig. 2 there are 3 types of curves :GPA represent students' average according to their final grade point average in middle school, RL represent students' average after choosing a FoS in accordance with the current system and RMS represent students' average after using RMS method. The first observation in this figure is for Student 1'Student 1', who has a GPA of 12.83, after choosing a FoS according to the current system, his average decline and so his level, but if he chooses a FoS according to the RMS method his average becomes 15.34 which reflect a considerable progress in his level, this is available also for the majority of students. Consequently, if the student choose his career by himself or guided by school counselors, his level might increase or decrease. But, if he is guided by such a system, he will be sure that it's the most level he can achieve (according to his actual abilities). Consequently, 
Table 3. students' Assignment.

\begin{tabular}{|c|c|c|c|c|c|c|c|c|c|c|c|c|c|c|c|}
\hline \multirow{2}{*}{$\begin{array}{c}\text { St/SS } \\
\text { St/FoS }\end{array}$} & \multicolumn{3}{|c|}{ ES } & \multicolumn{2}{|c|}{ MS } & \multicolumn{2}{|c|}{ LHS } & \multicolumn{2}{|c|}{ EMS } & \multicolumn{2}{|c|}{$\mathbf{A E}$} & \multicolumn{2}{|c|}{ IT } & \multirow{2}{*}{$\begin{array}{l}\mathbf{A A \mathbf { A }} \\
\mathbf{A A \mathbf { A }}\end{array}$} & \multirow{2}{*}{ GPA } \\
\hline & SLE & $\overline{\mathbf{P C}}$ & $\overline{\mathbf{A S}}$ & MSA & MSB & $\overline{\text { Lt }}$ & HS & ES & $\overline{A c}$ & $\overline{\mathbf{A L}}$ & SC & Mc & EI & & \\
\hline St 1 & 12.08 & 11.70 & 11.97 & 11.49 & 11.41 & 13.52 & 13.96 & 13.14 & 13.05 & 15.34 & 15.08 & 11.82 & 11.75 & 12.41 & 12.83 \\
\hline St 2 & 14.81 & 14.92 & 14.86 & 15.14 & 15.05 & 13.44 & 13.32 & 14.23 & 14.38 & 13.03 & 13.54 & 14.68 & 14.78 & 12.36 & 13.67 \\
\hline St 3 & 10.73 & 10.73 & 10.94 & 11.27 & 11.84 & 10.96 & 11.60 & 12.41 & 12.10 & 9.81 & 11.08 & 11.84 & 11.72 & 10.82 & 11.00 \\
\hline St 4 & 10.16 & 10.81 & 10.46 & 11.41 & 12.54 & 8.08 & 7.76 & 9.32 & 9.57 & 7.25 & 8.74 & 13.76 & 13.47 & 10.91 & 10.25 \\
\hline St 5 & 13.22 & 13.16 & 13.00 & 13.00 & 12.68 & 10.48 & 10.16 & 11.14 & 11.24 & 10.69 & 10.62 & 12.68 & 12.67 & 10.50 & 11.67 \\
\hline St 6 & 10.05 & 9.89 & 10.23 & 9.78 & 9.70 & 14.80 & 14.76 & 13.09 & 12.90 & 14.50 & 13.36 & 9.18 & 9.36 & 12.64 & 11.67 \\
\hline
\end{tabular}

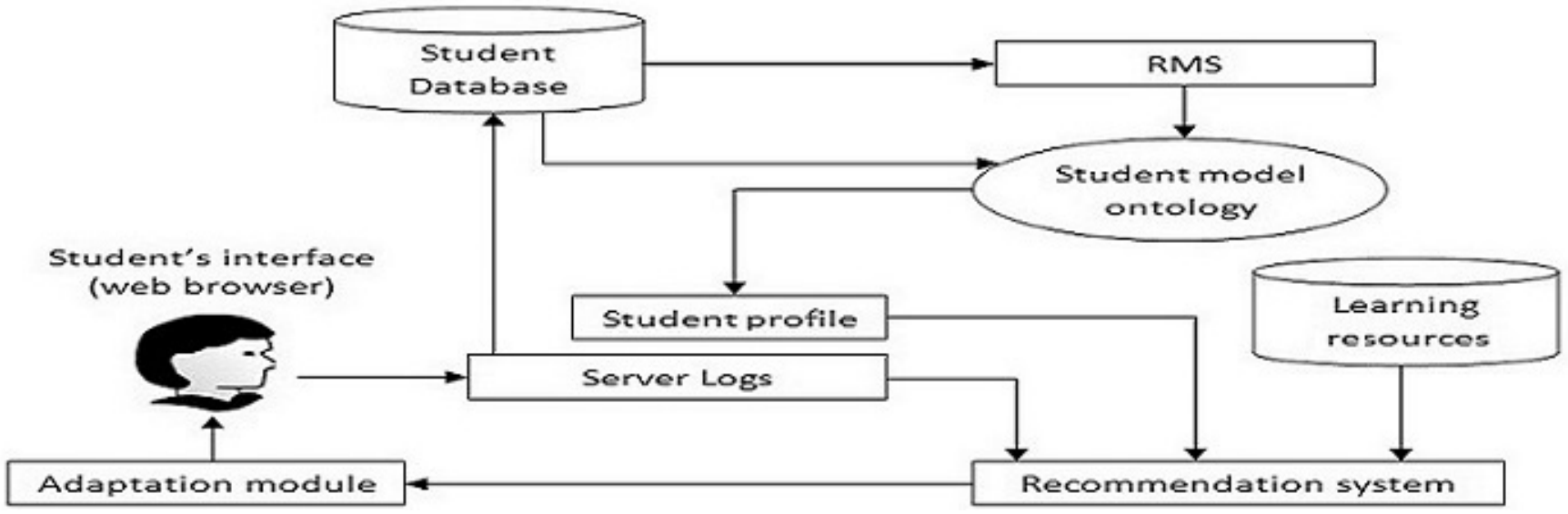

Fig. 3. System architecture.

once the student choose a way, he has a good chance to improve his school level.

\section{THE CLIENT INTERFACE CONTENT PERSONALIZATION BY USING ONTOLOGY}

The objective of web personalization is to give students a content they want or need. Thus, knowing their profiles is an important task for content recommendation in web personalization. For this, Some applications directly involve user data through surveys, questionnaires, submitting personal information during registration, and so on. In this case, the type of content may be provided for users according to their choices and preferences [23]. Some other applications, building user profiles in accordance with $\log$ files, are engaged without the user direct involvement [24]. However, a hybrid approach will be proposed for this task. It's based on student's abilities defined by RMS method. This section will elucidate how the system will adapt its content depending on student's profile. Indeed, the main axis to select the educational resources that will fuel the web interface, is based essentially on the FoS assigned to student as well as the evolution of its interaction with the system. The student's profile includes preferences learning style, his level, his achievements and shortcomings. This profile is modeled by ontology. In this way, the profile of each student is described by annotations in accordance with ontology. With these profiles the system identify the student's needs in order to promote the success of his learning. Finally, the system is able to adapt at first its contents according to the student's profile, and in a second time to evolve this same content depending on the student-system interaction by exploiting traces left by the student on web. To build the adequate recommendation for community of students, the proposed system is composed of four main parts (Fig. 3) :

-An adaptation module : The students' activities data (Pedagogical content used, test results, marks earned, web pages navigated) are collected within this module, in addition to the registration form and the students' sessions.

-A recommendation system : This module is based on student's profile and student's history to recommend the appropriate learning resources. Then, the list of recommended actions and recourses are sent to the adaptation module.

-A student model ontology : The ontological schema has a main role in constructing the student's profile.

-A 'RMS' model : The Recommendation Method for students is based on students' previous school marks (psm) in order to provide their results to ontology.

The main goal of system's evolutionary part, is to support students throughout their schooling career, in order to enabling them to make their best choice. Making a good choice will facilitate the learning task for any e-Learning system.

\section{CONCLUSION}

Helping students in improving their school levels will have a considerable impact in social and economic aspect. In one hand, students will diversify their knowledges and skills, make better choice of careers and consequently they will increase their standard of living. In the other hand, that will support economic development goals. However, such a system will enable 
students to manage and plan their learning and career pathways in accordance with their abilities and interests in education and will contribute to their personal fulfilment. In addition this solution will also support students through pedagogical content presented and managed by the E-Learning framework. The later will help student to understand and to go deeply in the courses that interested them. The proposed student's model will enable to optimize the educational recommendation through an adaptive system. To do this, RMS model based on students' school marks will be applied as a first step. Then, the proposed method based on ontology will allow the student to be orientated optimally and to satisfy several criteria and requirements. Thus, students can learn more conveniently than before with a system that meets their needs and interests. The evolutionary aspect of this system is revealed through the possibility of students migration from one profile to another dynamically, depending on their interaction with system. Future work involves the study of assignment's influence on Student-System interactions.

\section{REFERENCES}

[1] Swan, K. (2003). Learning effectiveness: what the research tells us. In J. Bourne, \& J. C. Moore (Eds.), Elements of quality online education, practice and direction (pp. 1345). Needham, MA: Sloan Center for Online Education.

[2] Klasnja-Milicevic, A., Vesin, B., Ivanovic, M., Budimac, Z. (2011). E-Learning personalization based on hybrid recommendation strategy and learning style identification. Computers \& Education 56, 885-899.

[3] Doucet, A., Lumineau, N., Berrut, C., Denos, N., Rumpler, B., Rocacher, D., Boughanem, M., Soule-Dupuy, C., Mouaddib, N., Kostadinov, D. (2004). Action Specifique sur la Personnalisation de l'Information. Rapport de fin de contrat, Groupe MRIM - CLIPS-IMAG.

[4] Abbas, K. (2008). Personalized access to information system: Application to medical domain. Ph.D. thesis, INSA de Lyon.

[5] Ioannidis, Y. E., Koutrika, G. (2005). Personalized systems: Models and methods from an ir and db perspective. In $\mathrm{K}$. Bohm, C. S. Jensen, L. M. Haas, M. L. Kersten, P. - A. Larson, B. C. et Ooi (Eds.) VLDB, p. 1365.

[6] Kathia Marcal de Oliveira, Firas Bacha, Houda Mnasser, \& Mourad Abed (2013). Transportation ontology definition and application for the content personalization of user interfaces. Expert Systems with Applications 40, 3145-3159.

[7] P. Resnick and H.R. Varian, Recommender systems, Communications of the ACM, 40 (1997) 56-58.

[8] Prof. Dr. Arif ALTUN 'Ontologies for Personalization: A new challenge for instructional designers', Procedia - Social and Behavioral Sciences 64 (2012) 691 - 698, Elseiver.

[9] Sawang, S., Newton, C., \& Jamieson, K. (2013). Increasing learners' satisfaction/intention to adopt more e-learning. Education + Training, 55(1).

[10] Manouselis, N., Drachsler, H., Vuorikari, R., Hummel, H. and Koper, R. (2010) Recommender Systems in Technology Enhanced Learning, in Kantor P., Ricci F., Rokach L., Shapira, B. (Eds.), Recommender Systems Handbook: A Complete Guide for Research Scientists \& Practitioners.

[11] Haiyang Jia, Minhong Wanga, Weijia Ran, Stephen J.H. Yang, Jian Liao, Dickson K.W. Chiu (2011). Design of a performance-oriented workplace e-learning system using ontology. Expert Systems with Applications, 38, 33723382.
[12] Abel, F., Bittencourt, I., Costa, E., Henze, N., Krause, D., \& Vassileva, J. (2010). Recommendations in Online Discussion Forums for E-Learning Systems. IEEE transactions on learning technologies, VOL. 3, NO. 2.

[13] N. Soonthornphisaj, E. Rojsattarat, \& S. Yim-ngam (2006), Smart E-Learning Using Recommender System, Proc. Intl Conf. Intelligent Computing.

[14] Elyusufi, y., Seghiouer, h., Benkaddour, a. (2013). Customization of Human-Computer Interface Guided by Ontological Approach in Web 2.0. International Journal of Computer Applications (0975 8887). Volume 81 - No. 5.

[15] R. Burke, 'Hybrid Recommender Systems: Survey and Experiments' User Modeling and User-Adapted Interaction, vol. 12, no. 4, pp. 331-370, 2002.

[16] Wiley D. 2000. 'The Instructional Use of Learning Objects' AECT.

[17] Mizoguchi, R.(1998). A Step Towards Ontological Engineering. 12lh National Conference on AI of JSAI, pp.24-31. Online: http://www.ei.sanken.osaka-u.ac.jp/english/ step-onteng.html.

[18] Psyche, V., 2007. Role of ontologies in ILE engineering : Case of assistance system to pedagogical design. Ph.D.Thesis, Department of Computer Science, University of Quebec in Montreal(UQAM).

[19] Noy, N.F., \& McGuinness, D.L. (2001). Ontology development 101: A guide to creating your first ontology, Citeseer.BR, Kuo-Kuang Chu.

[20] Nilsson M., Palmer M. et Naeve A. 'Semantic Web Metadata for e-Learning: Some Architectural Guidelines'. Proceedings of the 11th World Wide Web Conference (WWW 2002), Hawaii, USA, 2002.

[21] Ronald G. 'Sultana Guidance policies in the knowledge society. Trends, challenges and responses across Europe. A Cedefop synthesis report' Luxembourg: Office for Official Publications of the European Communities, 2004 (Cedefop Panorama series; 85 - ISSN 1562-6180).

[22] C. Mangard, A. Channouf. 'Do orientation decisions depend of social stereotypes? Under what conditions?' European Review of Applied Psychology, Volume 61, Issue 3, Pages 161-170, 2011, ELSEIVER.

[23] Cheng Chih Chang, Pei-Ling Chen, Fei-Rung Chiu, Yan-Kwang Chen 'Application of neural networks and Kano's method to content recommendation in web personalization', Expert Systems with Applications 36 (2009) 5310-5316, Elseiver.

[24] Liu, H., Keselj, V. (2007). Combined mining of web server logs and web contents for classifying user navigation patterns and predicting users' future requests. Data and Knowledge Engineering, 61, 304-330. 